\title{
PARADOJAS POLÍTICAS E INSTITUCIONALES DEL CONSTITUCIONALISMO
}

\author{
José Sánchez Parga*
}

\begin{abstract}
Hay que partir del presupuesto que estaríamos asistiendo hoy a la constatación terminal de lo que hace más de un siglo había pronosticado la crítica marxista de la democracia burguesa o democracia formal: “icómo integrar las poblaciones inferiores por su nivel económico y social en una nación fundada sobre el principio de la igualdad política y jurídica?... la igualdad

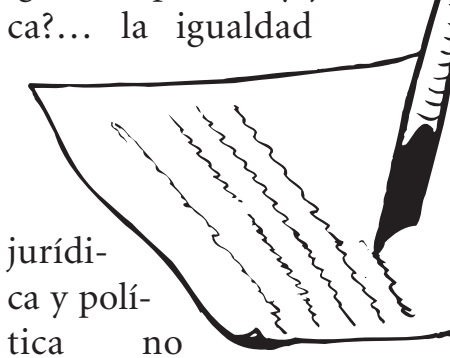

puede compensar las brutales desigualdades del orden económico ni real ni simbólicamente"1. Hoy sabemos más bien que esa democracia $\tan$ formal y de mercado ha servido exactamente para todo lo contrario

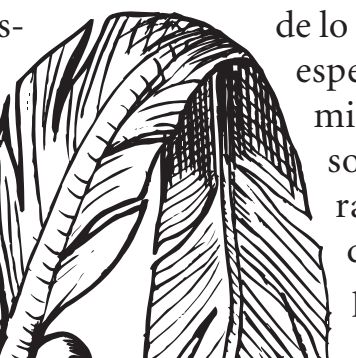

de lo que se hubiera podido esperar de ella: agravamiento de las diferencias socio-económicas y radicalización de las desigualdades sociopolíticas.

Los actuales procesos por los que atraviesan las democracias en todo el mundo, y los fenómenos que de manera particular caracterizan muchas de ellas, no son ajenos al real y profundo fracaso de la democracia en la actual sociedad de mercado, o a las tortuosas inviabilidades de lo que se ha denominado "democracias de mercado". Tales fracasos democráticos, perversiones y deslegitimación de la democracia han adoptado modalidades muy diversas según las regiones y los países. Pero lo que es evidente en todo el mundo, en particular en América
\end{abstract}

* Asesor Académico Universidad Politécnica Salesiana, investigador del Centro Andino de Acción Popular (CAAP).

1 Dominique Schnapper, La communauté des citoyens. Sur l'idée moderne de nation, Gallimard, Paris, 1994:149s 
Latina y concretamente en Ecuador es que la democracia del ajuste estructural, de la dominación neoliberal, de la sociedad de mercado lejos de reducir las diferencias económicas ha servido para aumentar las desigualdades y violencias sociales junto con la concentración y acumulación de riqueza.

No al margen de este contexto general, sino en el centro de su problemática se inscribe hoy la actual coyuntura constitucionalista.

A una tendencia generalizada en todas las democracias modernas de reforzar los poderes del Ejecutivo en detrimento de los Legislativos y Judiciales (e incluso Constitucionales) se ha asociado un fortalecimiento aún mayor de los poderes Presidenciales (en las democracias no-parlamentarias). A tal reforzamiento han contribuido en muchos casos las recientes reformas constitucionales. Pero un caso particular de este fenómeno son las nuevas Constituciones - $\mathrm{O}$ Asambleas Constitucionales- emprendidas por los gobiernos de Chávez, Morales y Correa, cuyo objetivo - más allá de la mencionada concentración y acumulación de poderes presidenciales - es dotarse de un nuevo marco jurídico, político e institucional, que además de una reforma del Estado permita un radical reordenamiento de las políticas gubernamentales.

Esta suerte de "empoderamiento constitucional", entendido como la forma de reforzarse y legitimarse un gobierno, sostenido por un "movimientismo constitucionalista" desde la misma sociedad civil, responde en los tres países latinoamericanos no sólo a un proyecto de gobierno, que en cierto modo subvierta casi dos décadas de políticas neoliberales, sino también a compensar un profundo déficit institucional y en particular de aquellas instituciones democráticas de la representación política. De hecho, la Asamblea Constituyente, avocada en la actual coyuntura a redactar una nueva Constitución, aparece hoy legitimando un nuevo representativismo político, según el cual los políticos se candidatizan y son elegidos por considerarse representativos de quienes piensan como ellos y tienen sus mismas posiciones políticas; a diferencia de la representación política, según la cual los representantes representaban determinadas fuerzas sociales e intereses colectivos, o al menos los de sus electores ${ }^{2}$. También el mencionado cons- 
titucionalismo contradeciría o atenuaría en parte los populismos nacionalistas, que se achacan a los actuales gobiernos, criticando que tal vía popular nacionalista no puede ser una solución para los países latinoamericanos, cuando las otras soluciones impuestas durante las dos últimas décadas (ajuste, privatizaciones, endeudamiento, inversión extranjera...) lejos de solucionar agravaron tales problemas. El presente estudio tratará analizar críticamente este constitucionalismo en el particular caso ecuatoriano.

\section{"Dificultades", “incertidum- bres" y "peligros" del reto constitucionalista}

El Presidente Correa, su actual gobierno, todo el movimiento constitucionalista que surgió con su campaña electoral y se ha ido consolidando en torno a la Asamblea constituyente, junto con gran parte de la opinión pública nacional, quizás no hayan tomado plenamente conciencia de lo que implican las ambiciosas reformas constitucionales e institucionales puestas en juego. De estos riesgos y retos políticos, propios de toda gran transformación institucional, advertía ya Maquiavelo: "nada hay más difícil de tratar, ni más incierto de conseguir, ni más peligroso de manejar, que ponerse al frente para introducir nuevos órdenes institucionales"3.

La razón principal del grave desafío, que supone esta vehemente voluntad de transformación constitucional, es el excesivo poder requerido para llevarla a cabo. Tal concentración y acumulación de poder en una sola persona es absolutamente necesaria no sólo para enfrentar las "dificultades", "incertidumbres" y "peligros" de una mutación del ordenamiento constitucional sino también porque "quienes quieren ejercer un poderío absoluto... deberán renovarlo todo". No otro es el precio a pagar, cuando "nada proporciona mayor mérito político que hacer nuevas leyes e instituciones"4. Ahora bien, en un contexto democrático todo aumento, concentración y acumulación de poder no se lleva a cabo sino es a costa de las otras fuerzas sociales y de los otros poderes políticos, y sobre todo a costa del reforza- 
miento de los contrapoderes. Lo cual acarrea siempre mayores riesgos y peores conflictos 5 .

De otro lado, cuanto mayor es el poder, las fuerzas e intereses investidos en las grandes transformaciones institucionales, tanto más se reforzarán las resistencias y confrontaciones a tales cambios. Esto significa, en primer lugar, no tanto ignorar y evitar los conflictos cuanto no subestimarlos; y en segundo lugar, conseguir nuevas y mayores fuerzas en los mismos cambios institucionales. En otras palabras, se necesita un excedente de poder tanto para destruir viejas instituciones y sus ordenamientos como para crear otras nuevas.

Ahora bien, la masa de normatividad constitucionalista requerida para destruir el anterior ordenamiento socio-político y económico, implementado por las fuerzas e intereses neoliberales, y para reorientar la sociedad y el Estado ecuatoriano hacia un desarrollo post-neoliberal, puede resultar tan pesada, que aplaste las ya frágiles y precarias condiciones y capacidades de institucionalidad del país. Resultado de ello sería la instalación de un enorme artefacto jurídico-constitucional, cuya super- estructura se encuentre totalmente desfasada de las reales estructuras de la sociedad ecuatoriana.

Aunque la sociedad ecuatoriana y sus instituciones políticas no habrían cambiado tanto en los diez últimos años, como para merecer una nueva Constitución muy diferente de la elaborada en 1998, lo que sí se ha modificado radicalmente es la instrumentalización que se hizo de aquella Constitución y la que se intenta implementar hoy: en ambos casos la Constitución fue utilizada para imprimir una determinada orientación al Estado, a las políticas de gobierno y a la misma sociedad. Es pues el cambio de orientación, lo que haría necesaria la nueva instrumentalización de la Constitución. En otras palabras, es la relación política respecto de la Constitución lo que se ha transformado. Aunque lo que de hecho está en juego es una doble versión y tratamiento políticos de lo que significa y hace una Constitución. Mientras que la de 1998 fue una Constitución - balance, que consolidaba una década de reformas y políticas neoliberales, la que se pretende actualmente es una Constitución programa, que no sólo frene y rectifi-

5 Tanto el proyecto constitucionalista de Chávez todavía fuertemente cuestionado como la fracasada Asamblea constituyente de Morales (instalada desde hace un año, pero aún sin reglamento) demuestran las dificultades, incertidumbres peligros de reformas constitucionales aun cuando se encuentren tan sostenidas y legitimadas socialmente. 
que casi dos décadas de dominación neoliberal, sino que sobre todo imprima una nueva orientación más social o socialista a las instituciones del Estado y a las políticas gubernamentales ${ }^{6}$.

La actual coyuntura nos pone en presencia no sólo de dos modelos de constitucionalismo, sino sobre todo de dos concepciones del sistema político y de la misma formación de la sociedad nacional: ya que una cosa es constituir lo ya instituido en la sociedad y en su sistema político, y otra cosa muy diferente es llegar a institucionalizar una Constitución. Resulta extremadamente ilusorio, a la vez que representa un enorme desafío, el optar en el Ecuador actual por esta última versión y tratamiento constitucionalistas, cuando el gran déficit y fracaso histórico es la precariedad institucional tan generalizada en el ámbito político como en el social; en términos más precisos, la incapacidad de institucionalizar procesos sociales y políticos.

No hay que olvidar hoy el fuerte coyunturalismo político, que influyó no sólo en la Constitución de 1978, producto de un pacto impuesto por la transición democrática, y en la
Constitución de 1998 protagonizada por Oswaldo Hurtado, producto también del pacto no menos impuesto por una gobernabilidad tan ideológica e influida por coerciones externas y transnacionales como por los intereses económicos y fuerzas neoliberales dominantes en ese entonces sobre la sociedad ecuatoriana.

Estos planteamientos además de explicar el actual proceso constitucionalista, las tensiones y conflictos en torno a él, permitiría desarmar ciertas críticas, que reprochan al actual constitucionalismo de "nominalista" y "fetichista", ya que en lugar de producir una Constitución que refleje la realidad política e institucional del país, más bien se pretende atribuir a la Constitución el poder crear un modelo de sociedad, un orden institucional y una cultura política y ciudadana, que realmente no existen. Una tal pretensión implicaría no sólo abrir una brecha entre la realidad y sus ideales, sino sobre todo invertir la causalidad política, que en lugar de actuar desde la sociedad y sus instituciones hacia la Constitución, presupone muy ilusoriamente que es la Constitución y desde ella, que sería posible producir sociedad e institucionalidad política.

\footnotetext{
6 Sobre este doble modelo de Constitución, que en realidad corresponde a un doble modelo de sistema político cfr. Guiseppe de Vergottini, art. Constitución, en N. Bobbio et al. Diccionario de Política, Siglo XXI, México, 1988:325.
} 
En este sentido, se ignora que la Constitución "no inventa o promueve de manera voluntarista un orden de libertad. Da una nueva forma política al orden de libertad en el que ya vive" una sociedad ${ }^{7}$. En otras palabras, la normatividad de la Constitución no puede ser considerada ni tratada como algo exterior a la misma sociedad y su sistema político, puesto que "la Constitución, en efecto, es la misma estructura de una comunidad política organizada, aquel orden necesario que deriva de la designación de un poder soberano y de los órganos que lo ejercen" 8 . Si por ello, "una Constitución es inmanente a una sociedad cualquiera" (según el mismo Matteucci), es preciso reconocer que es la sociedad la que hace la Constitución y no la Constitución que hace la sociedad.

Formulado en otros términos, lo que en la actual coyuntura parece contraponerse es, de un lado, un voluntarismo constitucionalista, promotor de importantes transformaciones políticas, y de otro lado, una realidad institucional, que limitaría y hasta frenaría tales cambios. Ante situación tan paradójica no cabría más solución para el proyecto consti- tucionalista, que en lugar de superabundar o agotarse en grandes declaraciones y enunciados de principios, se centrara en las reformas institucionales, de tal manera que éstas pudieran operar como mediaciones efectivas de los posibles cambios constitucionales.

Cuando las leyes son demasiado distantes de las prácticas y conductas reales de la sociedad, aquellas se vuelven incapaces de regular éstas; las leyes por consiguiente deberían traducir de alguna manera las costumbres de una sociedad dada, so pena de una total ineficacia o de favorecer una desobediencia generalizada y constantes transgresiones; es decir un incivismo generalizado. Sin embargo, bien se podría objetar que las leyes no son necesarias en una sociedad, donde ya las costumbres son eficaces, y que por consiguiente las leyes sólo tienen por objeto normar e imponer constreñimientos, allí donde los hábitos y las costumbres de una sociedad son insuficientes e ineficientes para ordenarlas. Ambas posiciones lejos de excluirse se complementarían, pudiendo indicar los dos umbrales, en cuyo interior unas leyes y una constitución tienen con-

7 Javier Pérez - Díaz, Sueños y razón de América Latina, Taurus, Madrid, 2005.

8 Cfr. Nicola Matteucci, art. Constitucionalismo, en Norberto Bobbio et al. Diccionario de Política, Siglo XXI, México, 1988:349. 
diciones de posibilidad para ser efectivas y subsidiarias. En cualquier caso, el problema que la actual Constitución plantea reside en la ausencia de reales mediaciones institucionales entre las normas y directrices constitucionales y los distintos ámbitos de la realidad social y política; donde se pueda lograr un equilibrio entre la legalidad constituyente y la normatividad constituida.

\section{Contradicciones institucio- nales del constitucionalismo}

Retomamos el planteamiento anterior: formulado en términos simples, una Constitución tiene, en su sentido propio, un objetivo fundamental: constituir los procesos instituidos en la sociedad y su sistema político, garantizando su validez, impidiendo cualquier trasgresión y sobre todo sentando las bases para ulteriores desarrollos institucionales, ya que define las reglas del juego de todas las fuerzas y acciones sociopolíticas. Más difícil y aleatorio es el objetivo de instituir lo constituido por una Asamblea Constituyente en un texto constitucional; no sólo debido a la distancia retórica interpelativa que adquieren sus contenidos (sobrecargados de deber-ser) y las reales condiciones de su institucionaliza- ción, sino también porque una tal Constitución habrá de elaborarse sobre un proceso de desinstitucionalización. ¿Cómo, por consiguiente, establecer un nuevo ordenamiento constitucional sobre un viejo desorden institucional?

Este problema se encontraría agravado por un clima ideológico tan dominante como generalizado, en el que los intereses, necesidades y reivindicaciones se transforman fácilmente en derechos y son reivindicados como tales; como si dicha transformación en derechos fuera ya una garantía para la satisfacción de tales necesidades y reivindicaciones. El actual movimiento constitucionalista en parte se inscribe en dicho clima ideológico e interpelativo, y en parte prolonga su dinámica: transformar en derechos constitucionales todos aquellos intereses y necesidades, expectativas y reivindicaciones, que las institucionales sociales y políticas han sido incapaces de satisfacer y cumplir.

Dicha inversión de la causalidad entre Constitución y sociedad e instituciones políticas no sólo incurre en una suerte de fetichismo constitucionalista, según el cual los enunciados de la Constitución tendrían ya por sí mismos efectos en la sociedad y en sus actores, sino que sobre todo dis- 
pensaría a la misma sociedad, sus actores sociales y políticos, a las instituciones, organismos del Estado y sus gobernantes la tarea de emprender y llevar a cabo esa idea o proyecto de país que llegue a forjarse en una Constitución. Según esto, la hipertrofia constitucionalista responde en el fondo a una atrofia de las instituciones sociales y políticas, cuya incapacidad para producir los cambios se pretendería compensar o encubrir con una supuesta eficacia y retórica constitucionalistas, con poderes más interpelativos que efectivos. Formulado en términos opuestos y aún más radicales ¿en qué medida la hipertrofia constitucionalista no agrava en mayor grado la atrofia de las instituciones?

Tal sería el peor error de un constitucionalismo, que "supone una confianza excesiva en los textos constitucionales para renovar la sociedad, superar sus contradicciones, impulsar el progreso y resolver todos sus problemas" . El excesivo constitucionalismo, o la necesidad de incorporar a una Constitución no sólo demasiada carga legislativa sino también la mejor imagen que una sociedad quiere de sí misma, es decir convertir la Asamblea Constituyente en una Asamblea legislativa, todo ello pretendería compensar o en parte sustituir el déficit de institucionalidad política, y sobre todo un creciente defecto de Estado. Junto con una artificial y excesiva institucionalización de la política, el fetichismo constitucionalista puede acarrear una mayor atrofia institucional, la cual llegue a resultar tan nefasta para un gobierno democrático como para la misma vida política, ya que "un exceso de institucionalización de la política puede llegar a ser para la vida democrática tan contraproducente como la ausencia de instituciones sólidas" 10 .

Tras toda esta estrategia de la Asamblea de reunir poder legislativo y poder constitucional, y del Ejecutivo de reunir poder gobernante y poder estatal, poderes políticos y poderes administrativo-decisionales hay que entender un denodado intento por volver a juntar lo que tanto la dominación económica del mercado como los gobiernos e ideologías

9 Javier del Rey Morató, “Cultura política y Constituciones en América Latina”, en Nueva Sociedad, n. 210, julio - agosto, 2007:9.

10 Fernando Mires, “Estado y política. La lucha por la democracia en América Latina”, Nueva Sociedad, n. 210, julio-agosto, 2007: 146. 
neoliberales habían separado y distanciado cada vez más: el poder y la política $^{11}$.

Esta paradoja resulta tanto más contradictoria en la medida que los efectos de una Constitución dependen sobre todo de las instituciones sociales y políticas de la sociedad y más aún de manera muy particular de un Estado eficiente, tanto en la consolidación de sus instituciones como en sus funcionamientos. Así se resalta de nuevo la misma paradoja: ¿cómo una Constitución podrá institucionalizar sus contenidos, propuestas y proyectos constitucionales en una sociedad y en un sistema político siendo ellos mismos tan incapaces para institucionalizar procesos y procedimientos?

Se ha instaurado una ecuación muy difícil de resolver: por muy grandes que sean los poderes atribuidos a la Constitución, estos no garantizan ni un Estado eficiente ni un Gobierno eficaz, sobre todo cuando el Ejecutivo acumula tantos poderes decisionales y de intervención en tantos ámbitos de la realidad sociopolítica, que incluso llegue a paralizar o atrofiar las facultades institu- cionales del Estado. Se trata de Ejecutivos y Gobernantes atrapados por un sindrome gesticulatorio que de ninguna manera es sinónimo de efectividad ${ }^{12}$. Este mismo fenómeno puede ocurrir en el caso de las reformas e innovaciones, cuando falta una equilibrada correspondencia entre todo lo que se quiere y lo que se puede renovar; y más aún cuando pueden ser más efectivos aquellos cambios, que se realizan sin aparentes innovaciones. Aun cuando esto implique abdicar de los réditos políticos, que procuran las apariencias de los grandes cambios.

De otro lado, el Constitucionalismo respondería además a un defecto de legitimidad gubernamental, y de correspondencia entre la democracia gobernante y la democracia gobernada; de tal manera que la Constitución en lugar de ser el marco jurídico del ejercicio del gobierno y de la relación entre gobernantes y gobernados, se convierte en un instrumento de mediación del gobierno y de la relación entre ambos; instrumento tanto de la gubernamentalidad del gobernante como de la gobernabilidad de los gobernados. Lo cual

11 Siempre se podrá objetar que el poder está en todo lugar, local o capilarmente, en forma de fuerzas o de flujos, y que todo es política, pero en términos operativos no se pueden ignorar las diferencias institucionales de sus respectivos funcionamientos

12 Para demostrar que el fenómeno rebasa el espacio político latinoamericano, baste referirse al presidente Sarkozy como excelente ejemplo del síndrome gesticulatorio. 
implicaría una constitucionalización y judicialización de la misma política. Formulado en términos muy simples, si por una parte no se puede gobernar con la constitución en la mano, por otra parte tampoco se puede caer en la tentación de justificar constitucionalmente todas las políticas gubernamentales y hasta programas de gobierno. Esto, como se ha demostrado en las décadas neoliberales, sus políticas nunca contaron con la suficiente legitimidad.

Ahora bien, lo que en la actualidad justificaría la instrumentalización gobernante de una nueva Constitución, es que ya la Constitución anterior, que se pretende abrogar o reformar, había sido ya instrumentalizada por los gobiernos y fuerzas políticas precedentes. Según esto, la única manera de salir de esta espiral (o vaivén) constitucionalista, consistiría en redefinir un modelo de Constitución - marco y no seguir reproduciendo un modelo de Constitución - instrumento de gobierno, y que puede resultar tan efímera como la correlación de fuerzas que contribuyeron a su gestación.

Por consiguiente, el objetado "fetichismo constitucionalista" o "nominalismo constitucionalista" (Rey Morató), según el cual los hechos existirían por el simple acto de enunciarlos en la Constitución, no sería ajeno a un doble modelo de posible constitucionalismo, ni a la tensión y conflicto internos a toda Constitución entre su versión de principios formales y de principios materiales: entre el tipo de normatividad que va de la sociedad y del sistema político hacia la Constitución, para expresarse en ella, y la normatividad sostenida y movilizada por fuerzas sociales y poderes gubernamentales, que va de la Constitución hacia la sociedad y su ordenamiento político.

En el primer caso, de acuerdo a la versión más jurídica (material), la Constitución constituye "aquellos principios que están a la base del sistema normativo de todo ordenamiento político. En tal sentido la Constitución no es más que la norma de la norma, la cual enmarca toda producción de leyes y normas generales, y sobre todo presupone como ya constituido el ordenamiento socio-político sobre el cual se basa. En el segundo caso, la Constitución - programa "expresa de manera particularmente explícita un sistema orgánico de directivas a aplicar en breve, medio o largo plazo" (325).

Dadas estas dos tendencias constitucionales más o menos predominante cada una de ellas en todo proyecto de Constitución, de acuerdo a la historia y coyuntura políticas de 
cada sociedad, sería necesaria "la búsqueda de conciliación entre el sistema tendencial estático de sus normas originarias y las orientaciones impresas por las direcciones políticas, que los órganos constitucionales formulan bajo el empuje dinámico de las fuerzas sociales" (325). Es evidente que una hipertrofia de las dinámicas atribuidas a una Constitución además de irreales y utópicas pueden ser capitalizadas y utilizadas en beneficio de un autoritarismo político, más o menos justificado para explotar o llevar a cabo las potencialidades depositadas en la Constitución, legitimando así un ejercicio excesivo del poder gobernante. Como si los ambiciosos objetivos cifrados en la Constitución sirvieran de soporte a una también ambiciosa política gubernamental.

De otro lado el constitucionalismo en cuanto instrumento de gobierno contribuye a debilitar y deslegitimar el principal y más importante instrumento gubernamental: el mismo Estado. Y en este preciso sentido, al abolir las mediaciones institucionales y estatales, el mismo constitucionalismo responde a una aparente paradoja, que sin embargo se encuentra muy generalizada en la opinión pública latinoamericana: las preferencias por un autoritarismo democrático o por democracias autoritarias, que de alguna manera en parte legitimen la democracia y en parte se opongan o resistan a las dominaciones neoliberales, que se han ejercido a través de los mismos regímenes democráticos durante las dos últimas décadas ${ }^{13}$.

Una de las formas que puede adoptar el autoritarismo democrático producto de las nuevas reformas constitucionales es la concentración y acumulación de poderes en el Presidente con detrimento de los otros poderes del Estado. Más aún, el reforzamiento de los poderes del Ejecutivo y en particular de los personales poderes presidenciales contribuye a una mayor fragilización de las instituciones. Hay que reconocer, sin embargo, que lejos de tratarse de un fenómeno excepcional (exclusivamente latinoamericano), responde más bien a un proceso generalizado en todas las democracias actuales, incluso las más liberales (EE.UU. y GB) y republicanas (Francia).Tal

13 Desde hace una década en América Latina la insatisfacción por la democracia no ha cesado de aumentar; en Ecuador la satisfacción por la democracia había descendido ya entre 1996 y 2003 del 34\% al 23\%. Cfr. CLACSO, Latinbarómetro 2003. Informe Resumen. La Democracia y la Economía, www.latinbarometro.org Octubre 2003. Para un desarrollo más amplio de este tema cfr. J. Sánchez Parga, ¿¿Por qué se deslegitima la democracia? El desorden democrático", en Ecuador Debate, n. 62, agosto, 2004. 
autoritarismo democrático y presidencialista no sería más que la manifestación política con la que, en unos casos se expresan las fuerzas de los mercados y los poderes económicos, $\mathrm{y}$ en otros casos las resistencias a dichas fuerzas y poderes de la dominación capitalista y neoliberal. ¿Dónde está la diferencia? Mientras que en los gobiernos y Ejecutivos neoliberales la concentración y acumulación de poder se ejercen en contra de los principios democráticos y de las mismas instituciones públicas del Estado en beneficio de los intereses y fuerzas del mercado y del gran capital, por el contrario aquellos gobiernos y Ejecutivos que pretenden resistir a la dominación capitalista, necesitan así mismo una excesiva concentración y acumulación de poder, no sólo para resistir a los organismos nacionales e internacionales del capital y del mercado, sino también para llevar a cabo políticas públicas, más sociales y redistributivas.

Lo que ha ocurrido de manera generalizada en las democracias actuales, es que el constitucionalismo fundamentado en el principio de la separación de poderes y división de los órganos y funciones del Estado se ha convertido en un serio impedimento para el ejercicio político del gobierno (cualquier que sea su perfil ideológico), ya que en parte le resta poder frente a las otras fuerzas y poderes económicos, sobre todo frente a los organismos internacionales, $y$ en parte tiende a frenar decisiones y actuaciones gubernamentales cada vez más urgidas y apremiadas por las nuevas temporalidades de la globalización y las aceleraciones de la economía y la informática. Por eso, si el más fundamental principio constitucional ha sido siempre la limitación del gobierno por el derecho, nada más obvio y comprensible (no necesariamente justificable), que el neo-constitucionalismo pretenda más bien someter a los proyectos gubernamentales el mismo marco jurídico de la Constitución. Lo cual explica también que el nuevo autoritarismo democrático trate de investirse y legitimarse constitucionalmente.

Y esto mismo también da cuenta de ciertos abusos o manipulaciones constitucionales, cuando se extrapolan ciertos principios: por ejemplo, que el poder constituyente sea superior al poder legislativo, pues enmarca las competencias jurídicas de este, no justifica que aquel pueda ejercerse sobre este. La razón es obvia: mientras que la división de poderes hace que las funciones de estos se complementen y puedan supeditarse entre sí de manera recíproca, la separación de poderes impide que ningu- 
no pueda ejercerse sobre los otros o en detrimento de los específicos poderes respectivos. Sin embargo, hoy ya no se puede plantear este género de conflicto político como una "pugna de poderes", pues lo que está en disputa es una pugna de fuerzas e intereses económicos, que se proyectan en el escenario político ${ }^{14}$.

Según esto las actuales "pugnas de poderes", con la diversa morfología que pueden adoptar, son el efecto de otras fuerzas e intereses particularmente económicos, que se ejercen sobre los organismos del Estado, los dividen y confrontan entre sí. Hay que tener en cuenta, que la dominación e influencia neoliberales y de los sectores económicos dominantes, nacionales e internacionales, tienden a ejercerse de manera muy efectiva no tanto a través de uno u otro de los poderes del Estado, sino precisamente en su separación, y en las divisiones y pugnas entre en Ejecutivo, Legislativo y Judicial. O considerado desde otra perspectiva: es a través de la debilidad de los poderes democráticos, que mejor se ha impuesto la dominación neoliberal ${ }^{15}$.
En el caso ecuatoriano (como el de Chávez en Venezuela y Evo Morales en Bolivia) sólo un tal concentración y acumulación de poderes presidenciales permitirían al Ejecutivo emprender políticas y programas de gobierno, en contra de las fuerzas económicas y de la ideología neoliberal dominantes en la sociedad, y sobre todo en contra de los intereses y poderes de los capitales transnacionales. Cuando desde hace una década ya más del 52\% de la opinión pública latinoamericana y en mayor porcentaje la ecuatoriana, prefería cada vez más gobiernos no democráticos pero que "resuelvan los problemas económicos", es preciso deducir de esto dos conclusiones: que la democracia realmente existente sólo beneficiaría a un porcentaje cada vez menor de la población, y que de los gobiernos autoritarios o "no-democráticos" como de su resolución de los problemas económicos se esperaría una reducción de las diferencias económicas y las desigualdades sociales.

En este contexto, las fuerzas sociales y políticas, integrantes del movimiento o movilización constitucionalista, que no sólo dominan mayoritariamente la Asamblea Cons-

14 Cfr. J. Sánchez Parga, La pugna de poderes. Análisis crítico del sistema político ecuatoriano, CONUEP / Pontificia Universidad Católica del Ecuador, Quito, 1996.

15 En este sentido el caso boliviano es muy ilustrativo. Cfr. Jorge Komadina \& Céline Geffroy, El poder del movimiento político. Estrategia, tramas organizativas e identidad del MAS en Cochabamba (1999-2005), Universidad Mayor de San Simón, La Paz, 2007. 
tituyente sino que además representan la plataforma del actual gobierno y de sus futuras políticas gubernamentales, dichas fuerzas socio-políticas difícilmente se limitarán a pactar un texto constitucional, cuando fácilmente podrán imponer uno propio. Sin un tal "compromiso constituyente, inevitable si no se quiere arriesgar una imposición unilateral y autoritaria de una constitución partidista" (de Vergottini, o.c., pg. 327s), no se sin lograría un dispositivo institucional, de organización del Estado y del sistema político, capaz de remitir a actuaciones y realizaciones sostenibles en el futuro, y que justo por su origen comprometido tenga un carácter polivalente, el cual se preste a interpretaciones potencialmente diversas o divergentes de las normativas formales de la Constitución.

Cuando la correlación de fuerzas es tan ventajosa, mayor es el riesgo y la tentación de reproducir en la Asamblea constituyente una dictadura de la mayoría, que tan rara ha sido regulando la acción parlamentaria del Congreso. $\mathrm{Y}$ en este sentido siempre cabe sospechar cuanto se quiere conseguir por vía constitucional, que nunca se lograría por la vía parlamentaria. Que la propuesta de Constitución sea lo menos impuesta por las fuerzas dominantes en la
Asamblea y lo más consensuada y pactada posible por todas ellas, debería ser un objetivo no sólo para lograr la máxima legitimidad, sino sobre todo para disminuir la distancia entre lo que se quiere y lo que se puede obtener con la Constitución. Puesto que las más tenaces limitaciones a las propuestas constitucionales en la actual coyuntura no proceden tanto de las fuerzas opositoras sino de las reales condiciones para su efectiva aplicación.

Una Asamblea Constituyente, dominada por una política de cambio del actual gobierno, se halla atravesada por unas fuerzas que pretenden modificar las reglas de la acción democrática, pero que a la vez se encuentran sujetas al imperativo de aplicar dichas reglas del régimen democrático. Locuaz no deja de provocar una cierta tensión política y un problema de legitimidad. Ahora bien, tanto al nivel mundial como a escala nacional, los gobiernos que intentan cambiar las reglas de los procedimientos democráticos enfrentan el meta-poder de la economía, del capital y del mercado, que no se ejerce ni por procedimientos democráticos ni a través de instituciones democráticas, pero sí condicionando y hasta determinando su ejercicio. A diferencia del poder político, gubernamental y estatal, "el 
poder del neoliberalismo reposa sobre una desigualdad radical en la medida que unos pueden infringir las reglas, mientas que otros no tienen el derecho para ello. La modificación de las reglas es y sigue siendo el privilegio revolucionario del capital. Todos los otros están condenados a la observancia de las reglas"16. Por consiguiente, cualquier modificación de las reglas de la acción política y democrática por parte de las fuerzas gobernantes aparece como una trasgresión en contra de aquellas reglas e instituciones socio-políticas establecidas por la sociedad de mercado. "El poder efectivo de los Estados se encuentra paralizado por la situación de bloqueo, en la que han sido puestos por efecto del neoliberalismo"; por efecto de lo que Beck llama la "neoliberalización del Estado"17.

Finalmente la actual coyuntura constitucionalista no puede dejar de procesar que la actual Asamblea constituyente, lejos de ser producto de un concertado acuerdo nacional de todas las fuerzas sociales y políticas, ha sido más bien resultado no sólo de la derrota de la clase política sino también de una profunda crispación y enfrentamiento entre el Congreso y el Ejecutivo. ¿Cómo, entonces, la inminente producción constitucional logrará tratar este fondo de crispación y de conflictividad de origen, para que no repercuta en sus resultados? En cualquier caso, la actual coyuntura constitucionalista abre un abanico de posibilidades y alternativas, ninguna de las cuales son por sí mismas "buenas" o "malas", y ni siquiera una combinación de ellas. El reto de la Asamblea constituyente consistirá en hacer lo mejor posible las opciones que emprenda, ya que sólo por sus resultados y consecuencias se podrá juzgar políticamente la futura Constitución.

\section{El Constitucionalismo y el optimum de poder gobernante}

Siempre resultará difícil estimar el optimun (y más aún el quantum) de poder para garantizar un buen gobierno, cuando la calidad de un gobierno se mide por su estabilidad y duración, sobre todo en un régimen democrático, y también porque de-

16 Ulrich Beck, Pouvoir et contre-pouvoir à l'ère de la mondialisation, Flammarion, Paris, 2003:31. Mientras que el poder político está siempre sujeto a su legitimación el meta-poder del capital no necesita esa misma legitimación.

17 Cfr. Ulrich Beck, 2003:180; 235. La neoliberalización del Estado consiste en organizar los aparatos estatales y su funcionamiento de acuerdo a los principios y orientaciones de las instituciones transnacionales de la economía capitalista global: cfr. Beck, p. 307. 
penderá mucho de los gobernantes o tipo de gobierno y de las circunstancias políticas, para establecer cuáles son los umbrales de poder, dentro de los cuales un gobierno podrá ejercerse en las mejores condiciones.

Hay que tener en cuenta, que si de un lado no es fácil gobernar bien, cuando falta el poder requerido, y sus fuerzas disponibles no alcanzan el umbral mínimo, por otro lado se volverá extremadamente peligroso que un gobierno disponga de un poder excesivo, que rebase el umbral suficiente. Es necesario reconocer, sin embargo, que en todo sistema democrático las mismas instituciones políticas son las encargadas de dotar y regular el quantum de poder mínimo exigido, para que la sociedad sea gobernable y el límite máximo de poder máximo para que el gobierno no se vuelva dictatorial o despótico.

En este sentido, por ejemplo, habría que considerar, cuánto ganó Chávez políticamente en su derrota de referendum para una reforma constitucional, la cual le proporcionaría un excesivo poder, pero también cuánto perdió una oposición con su victoria, al quedar desarmada de lo que fue su principal acusación contra Chávez: el pretender un poder dictatorial. Esta lectura política del caso venezolano, que podría extenderse al de Evo Morales en Bolivia, proporciona claves interpretativas muy apropiadas para el gobierno de Correa en Ecuador y su proyecto constitucionalista. Se trata de dos cuestiones casi de manual político. En primer lugar, se trata de saber siempre qué se puede ganar políticamente con una derrota, y qué se puede perder políticamente con una victoria; ya que en política nunca las victorias y las derrotas son completas y definitivas; lo cual significa, a su vez, conocer todo lo que se puede aprovechar de toda derrota y calcular las pérdidas de una victoria. En segundo lugar, hay que tener muy en cuenta que cuanto mayor es el poder acumulado y disponible, más difícil es gobernar dicho poder, siendo muchas veces el excesivo poder el que se vuelve contra el mismo gobierno y lo desgobierna.

Nunca el ejercicio del poder ha sido sinónimo de buen gobierno. $\mathrm{Y}$ no cabe duda que los actuales regímenes instalados en América Latina en su reacción contra-neoliberal y movidos por una fuerte y urgente voluntad de cambios sociales, corren el serio riesgo de confundir el hecho de gobernar con el ejercicio del poder.

De acuerdo a un principio fundamental republicano y democrático (que además se remonta a la antigua Roma), el poder constitucional, como todo poder absoluto, precisa- 
mente porque goza de facultades extraordinarias, se encuentra sujeto a estrictas limitaciones: a) su ejercicio en las tareas específicas para las que fue constituido; b) plazos determinados en parte condicionados al cumplimiento de dichas tareas, y no más allá de ellas; c) prohibición de legislar, puesto que las leyes sólo pueden ser competencia de poderes ordinarios, y nunca producto de poderes extraordinarios; d) prohibición de acceso directo e indirecto al erario o dinero público. La transgresión de cualquiera de estas limitaciones fundamentales podría comprometer la futura legalidad y legitimidad de una Asamblea Constituyente. 